\title{
Laccase engineering by rational and evolutionary design
}

\author{
Isabel Pardo $\cdot$ Susana Camarero
}

Received: 23 December 2014/ Accepted: 30 December 2014/Published online: 14 January 2015

(C) The Author(s) 2015. This article is published with open access at Springerlink.com

\begin{abstract}
Laccases are considered as green catalysts of great biotechnological potential. This has attracted a great interest in designing laccases a la carte with enhanced stabilities or activities tailored to specific conditions for different fields of application. Over 20 years, numerous efforts have been taken to engineer these multicopper oxidases and to understand their reaction mechanisms by site-directed mutagenesis, and more recently, using computational calculations and directed evolution tools. In this work, we review the most relevant contributions made in the field of laccase engineering, from the comprehensive study of their structure-function relationships to the tailoring of outstanding biocatalysts.
\end{abstract}

Keywords Laccase - Site-directed mutagenesis ·

Random mutagenesis · Directed evolution .

Computational simulation $\cdot$ Protein engineering

\section{Introduction}

Laccases catalyze the one-electron oxidation of a set of aromatic compounds at the $\mathrm{T} 1 \mathrm{Cu}$ site, coupled to the fourelectron reduction of oxygen to water at the trinuclear cluster (TNC) (Fig. 1). Even though they are widely distributed in nature, laccases produced by wood rotting and litter decomposing fungi are the most interesting from a biotechnological point of view due to their higher oxidative capabilities [1].

I. Pardo $\cdot$ S. Camarero $(\bowtie)$

Centro de Investigaciones Biológicas, CSIC, Ramiro de Maeztu

9, 28040 Madrid, Spain

e-mail: susanacam@cib.csic.es
The crystal structures of a number of laccases and related multicopper oxidases (MCOs) have been solved in the last two decades [3]. Typically, laccases show a three cupredoxin-domain folding although small laccases with only two domains (SLAC) have been described in Streptomyces [2]. The combination of these data with sitedirected mutagenesis and computational studies has provided valuable information regarding the main structurefunction relationships in these enzymes. Yet, some aspects of the reactivity of laccases remain as subjects of debate, such as how the range of redox potentials or the diverse substrate affinities is tuned among laccases, thus hindering their rational design.

In recent years, the demonstrated potential of laccases in a range of applications has motivated the progress of laccase engineering efforts. Directed molecular evolution is an extremely powerful approach to tailor enzymes a la carte for particular purposes of application by mimicking in the lab the key processes of natural evolution. Genetic diversity is first generated by means of mutagenesis and/ or recombination of a parent gene or a family of related genes. Once this variety is expressed in an adequate host, the mutant libraries are screened under a "selective pressure". The selected mutants are subjected to new evolution rounds until the desired property is achieved (Fig. 2). Directed evolution does not require previous knowledge of the protein structure or reaction mechanism, but it requires significant screening effort for the analysis of thousands of clones. The availability of reliable screening methods to differentiate the best mutants from the rest is one of the main bottlenecks for evolutionary design. The preferred high-throughput screening (HTS) methods for the directed evolution of laccases have been, so far, based on colorimetric activity assays $[4,5]$. 


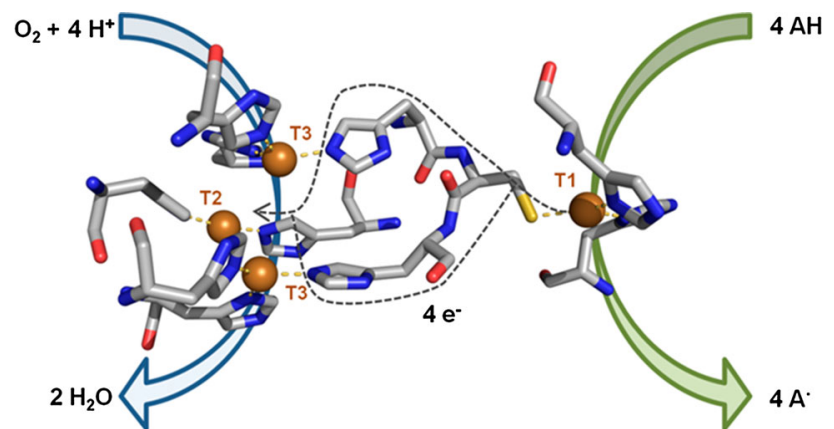

Fig. 1 Catalytic site of Pycnoporus cinnabarinus laccase (PDB 2XYB) showing the $\mathrm{Cu}$ sites for oxidation of the reducing substrate (T1), and for reduction of $\mathrm{O}_{2}$ (T2/T3) and proposed electron transfer pathway between both sites. Catalytic coppers are shown as spheres and coordinating residues are shown as sticks

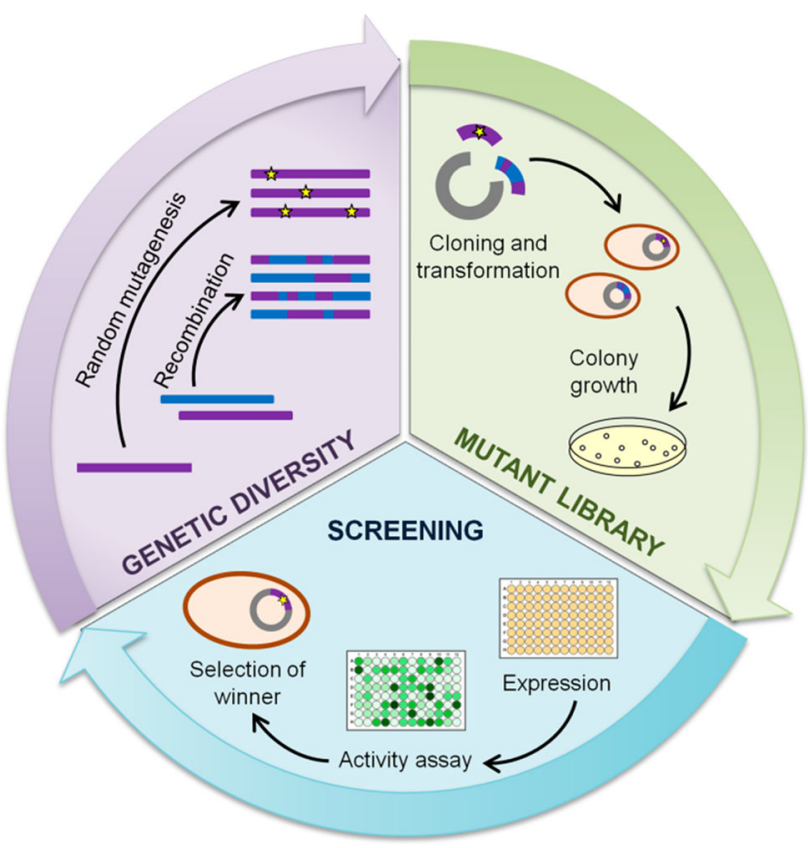

Fig. 2 Schematic representation of a directed evolution cycle comprised by three main steps: generation of genetic diversity, expression of the mutant library and screening and selection of the best mutants

Laccases are enzymes particularly suited for directed evolution. First, they are quite stable, which allows the accommodation of a fair number of mutations without obtaining an overly unstable protein. Second, they are catalytically versatile, so their activity can be enhanced towards a substrate that is not naturally well oxidized. Besides, the huge diversity of these enzymes allows one to choose the most suited scaffold for directed evolution. However, the difficult functional expression of recombinant laccases, particularly of fungal laccases, frequently makes their heterologous expression a target in itself for directed evolution prior to dealing with the improvement of activity/stability or specificity towards target compounds. Computational studies using protein structure prediction algorithms, molecular dynamics (MD) and hybrid quantum mechanics/molecular mechanics (QM/MM) calculations might aid the design of new laccase variants by reducing the experimental effort required to get the desired properties.

Here, we review the main inputs on rational and random design of laccases that have contributed to better understand the protein structure-function determinants and to improve the biotechnological applicability of these biocatalysts.

\section{From the understanding of the reaction mechanism}

Redox potential of $\mathrm{T} 1$ copper site, the role of the axial ligand

The $\mathrm{T} 1 \mathrm{Cu}$ center in bacterial laccases, as well as in the single blue copper proteins plastocyanin, azurin or rusticyanin, presents a distorted tetrahedral geometry constructed from a strong trigonal ligation (His-Cys-His) and a relatively weaker ligand in the axial position, generally a Met. In MCOs such as fungal laccases, ceruloplasmin or Fet3p, the Met ligand is replaced by a non-coordinating hydrophobic Leu or Phe residue, leading to a trigonal planar geometry [6].

The role of the axial ligand in tuning the redox potential of the $\mathrm{T} 1 \mathrm{Cu}$ centers has been extensively discussed due to the striking differences found among the different blue copper proteins. On one end, there is stellacyanin, a single blue copper protein with a redox potential $\left(E^{0}\right)$ as low as $+184 \mathrm{mV}$, which holds a Gln residue as axial ligand. On the other end, fungal laccases, ceruloplasmins and ferroxidases, all holding a Leu or Phe residue, have redox potentials roughly between +500 and $+800 \mathrm{mV}$. However, the small blue copper protein rusticyanin, with a redox potential over $+600 \mathrm{mV}$, shows a Met as axial ligand of the $\mathrm{T} 1 \mathrm{Cu}$ center. When the axial Met was replaced by Leu, the redox potential of rusticyanin raised $100 \mathrm{mV}$, while it decreased by a similar amount if Met was replaced by Gln [7].

The hydrophobicity of the axial ligand seems to correlate with the redox potential of the $\mathrm{T} 1 \mathrm{Cu}$ site in laccases [8], so that it might be considered as a rough indicator of their redox potential [3]. Laccases from plants (e.g., Rhus vernicifera) and bacteria (e.g., CotA laccase from Bacillus subtilis or SLAC), with a Met as axial ligand, show the lowest redox potentials (below $+500 \mathrm{mV}$ ). Middle-potential laccases (up to $+700 \mathrm{mV}$ ) mainly comprise ascomycete laccases and in general, with the exception of some basidiomycete laccases, have a Leu as non- 
coordinating axial ligand. Finally, high-redox potential laccases from basidiomycete fungi, with $E^{0} \approx+790 \mathrm{mV}$, commonly have a Phe residue in this position.

First site-directed mutagenesis studies on fungal laccases showed the exchangeable contribution to $\mathrm{T} 1 \mathrm{Cu} E^{0}$ of Phe and Leu as non-coordinating axial ligands. The replacement of the non-coordinating axial Leu ligand by Phe in Rhizoctonia solani $\left(E^{0}=+710 \mathrm{mV}\right)$ and Myceliophthora thermophila laccases $\left(E^{0}=+470 \mathrm{mV}\right)$ did not produce a significant increase in their redox potentials nor in the kinetics of the reaction [9]. Likewise, no significant alteration of Trametes villosa laccase properties was observed by changing the non-coordinating Phe axial ligand by Leu. By contrast, Phe replacement to Met resulted in $100 \mathrm{mV}$ redox potential decrease, distorted EPR spectrum, and modified optimum $\mathrm{pH}$ and kinetic constants during oxidation of phenolic substrates [10]. These effects were attributed to a perturbation of the geometry of $\mathrm{T} 1$ site. Accordingly, the electric state of the $\mathrm{T} 1 \mathrm{Cu}$ center of the MCO CueO from E. coli became similar to those of fungal laccases by changing the Met axial ligand to Leu, obtaining also significant increase of the redox potential [11]. Substitution of the axial Met with Leu or Phe in B. subtilis CotA laccase increased the redox potential by $100 \mathrm{mV}$, attributed to the weakening in the $\mathrm{T} 1 \mathrm{Cu}$ coordination [8], but at the same time, a major drop of the enzyme activity was observed because the electron transfer between $\mathrm{T} 1 \mathrm{Cu}$ and the TNC became unfavorable [6]. Interestingly, the Phe mutant laccase underwent an intense drop of thermodynamic stability due to the loss of copper from the T1 site, indicating that copper depletion is a key event in the inactivation of the enzyme [8].

Significant perturbation of the electronic structure of $M$. thermophila laccase $\mathrm{T} 1 \mathrm{Cu}$ site was obtained by changing the non-coordinating axial Leu to His. The tetragonal distortion of the $\mathrm{T} 1$ site led to a $\sigma$ overlap between the $\mathrm{Cu}$ and Cys(S) orbitals and to the green color of the His variant. The increased charge donation of the axial His coupled with the tetragonal distortion of the $\mathrm{T} 1$ site stabilized the oxidized state, hence lowering the redox potential (by $30 \mathrm{mV}$ ) and the reactivity of this site (tenfold decrease of $k_{\text {cat }}$ respecting the blue wild-type laccase) [12]. Directed mutagenesis of the axial Met ligand to His in another MCO, namely bilirubin oxidase, caused the loss of copper and the lack of activity. When the Met ligand was changed to Gln, a coordinating residue not naturally found in MCOs [6], T1 $\mathrm{Cu}$ parameters resembled those of single-copper stellacyanin, accompanied by a remarkable drop in the enzymatic activity and a $\sim 200 \mathrm{mV}$ decrease in the redox potential [13, 14].

Simulation studies corroborated the crucial role of the axial ligand in defining the chemistry and redox potential of $\mathrm{T} 1$ site. $\mathrm{QM}$ calculations of six $\mathrm{T} 1 \mathrm{Cu}$ sites (cucumber stellacyanin, Pseudomonas aeruginosa azurin, poplar plastocyanin, Coprinus cinereus laccase, Thiobacillus ferrooxidans rusticyanin, and human ceruloplasmin) confirmed that the low redox potential of stellacyanin was mainly due to the Gln ligand at the axial position, whereas the presence of a non-coordinating hydrophobic residue contributes significantly to the increased redox potentials in C. cinereus laccase and human ceruloplasmin [15]. QM/ $\mathrm{MM}$ and MD simulations data from Trametes versicolor laccase, CueO, CotA and SLAC also correlated at least in part the redox potentials with the hydrophobicity of the $\mathrm{T} 1$ $\mathrm{Cu}$ axial ligand [16].

The redox potential of $\mathrm{T} 1 \mathrm{Cu}$ centers is, however, tuned by other factors. One of them, first hypothesized by Piontek and co-workers [17], is the T1 Cu-His ligand distance. The elongation of the $\mathrm{Cu}-\mathrm{His}\left(\mathrm{N}_{\delta}\right)$ bond would account for a more electron-deficient copper and, consequently, for the observed higher redox potential in $T$. versicolor laccase as compared to $C$. cinereus laccase. Data from the crystal structure of Rigidosporus lignosus laccase [18] and MD simulations with CotA and SLAC [16] were mostly consistent with this hypothesis. However, although the protein fold could, in principle, modulate the $\mathrm{T} 1 \mathrm{Cu}$ redox potential by dictating the positions and orientations of the $\mathrm{Cu}$ ligands and adjusting the coordination bond strengths [15], overall, the relative changes in the $\mathrm{Cu}$-ligand distances within the rigid His $\left(\mathrm{N}_{\delta}\right)$-Cys $(\mathrm{S})$-His $\left(\mathrm{N}_{\delta}\right)$ environment can be assumed small, having a minimal effect on the $\mathrm{T} 1 \mathrm{Cu}$ redox potential for laccases. Conversely, the redox potential in MCOs is also influenced by the solvent accessibility, dipole orientation and $\mathrm{H}$-bonding outside the $\mathrm{T} 1 \mathrm{Cu}$ coordinating sphere. $\mathrm{T} 1 \mathrm{Cu}$ redox potential would increase with $\mathrm{N}_{\text {backbone }}(\mathrm{H})$-Cys(S) H-bonding, whereas backbone dipoles would increase the redox potential and dipoles between side-chain and solvent decrease it [16].

\section{Substrate binding pocket}

One of the main issues regarding the oxidation activity of laccases is the interaction between the substrate and the enzyme. Laccases with high sequence identity and a striking structural similarity might show quite different residues delimiting the substrate binding pocket (Fig. 3), although a comparable accommodation of the substrate is largely preserved by a similar spatial conformation, hydrophobic nature and recognition properties of the binding pockets. Even so, the contribution of the residues of the substrate binding pocket to the oxidation capability of these generalist oxidases is clearly indicated by the variety of substrate binding sites and the different kinetic behaviors of laccases with similar redox potentials [19].

$\mathrm{Xu}$ and co-workers [9] first evidenced the dependence of substrate binding and electron transfer on the features of 

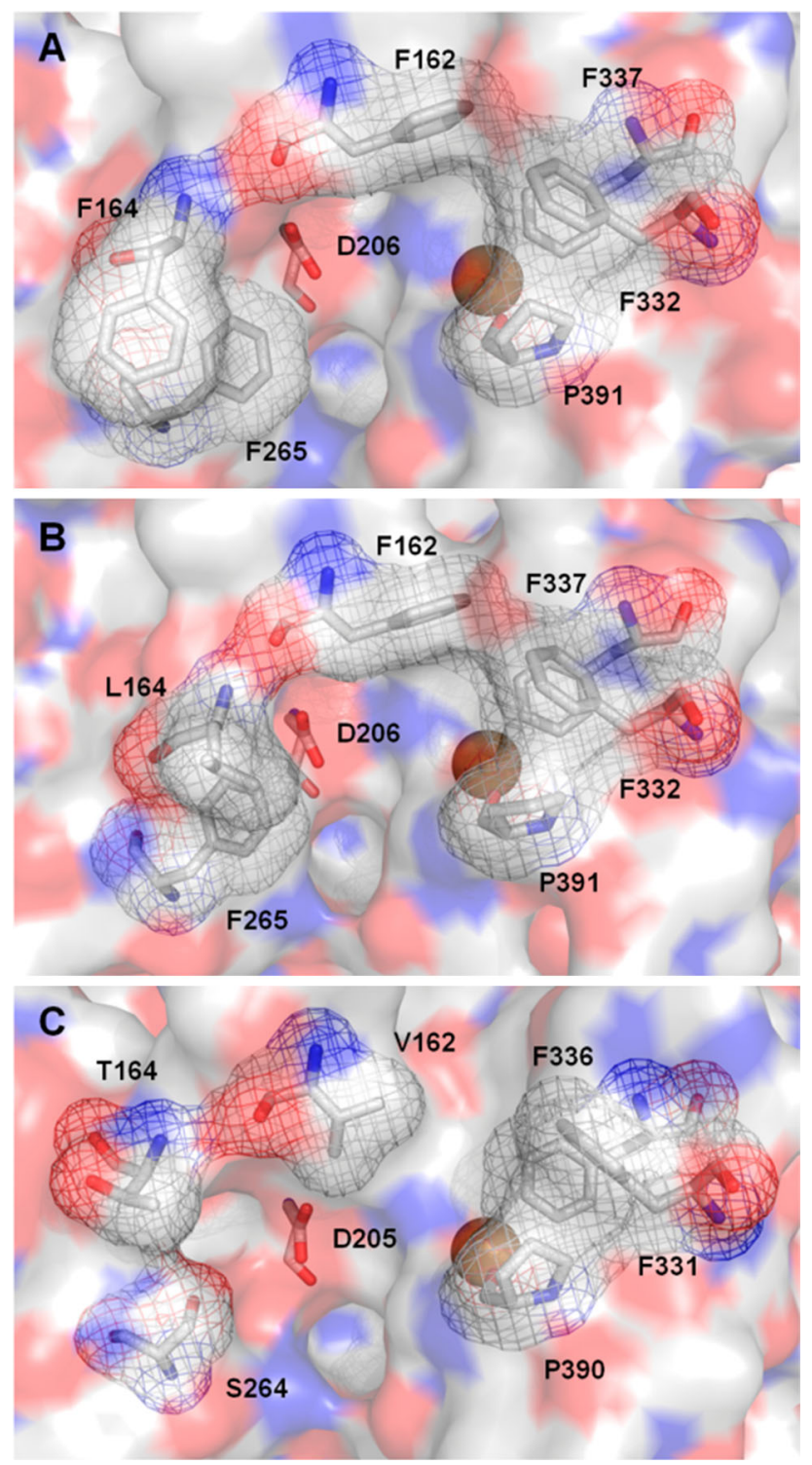

Fig. 3 Close-ups of the substrate binding pockets of a Pycnoporus cinnabarinus (PDB 2XYB), b Trametes versicolor (PDB 1KYA) and c Trametes trogii (PDB 2HRG) laccases

the enzyme pocket. The triple mutation of a tripeptide that is part of the substrate binding pocket in $R$. solani $\left(E^{0}=+710 \mathrm{mV}\right)$ and $M$. thermophila $\left(E^{0}=+470 \mathrm{mV}\right)$ laccases (LEA and VSG, respectively) caused a remarkable drop in $k_{\text {cat }}$ and increase of $K_{\mathrm{m}}$ but no change in the redox potential of $\mathrm{T} 1 \mathrm{Cu}$. These changes were attributed to electrostatic and steric hindrances to substrate docking introduced upon mutation.

The relative contribution of steric and redox features of putative substrates in determining their susceptibility to laccase oxidation was investigated by Tadesse and coworkers [20] in T. villosa $\left(E^{0}=+790 \mathrm{mV}\right)$ and $M$. thermophila $\left(E^{0}=+470 \mathrm{mV}\right)$ laccases. In spite of $\Delta G^{0}$ between the substrate and $\mathrm{T} 1 \mathrm{Cu}$ site being the ratedetermining reaction step, some of the substituted phenols and anilines investigated failed to be oxidized by the enzyme, even if they had a well-suited redox potential. A relationship between phenolic maximum dimension and substrate consumption was put forward. A steric threshold of 11-12 $\AA$ was reportedly dependent upon the distance between two Phe residues, Phe332 and Phe265, which mark the entrance to the active site. To overcome the protein steric restraints and improve its activity towards bulky phenols, four Phe residues of the substrate binding pocket of $T$. versicolor laccase $(\mathrm{TvL})$ were subjected to site-directed mutagenesis [21]. Overall, the amino acid changes of the enzyme pocket mostly conditioned interactions needed for the correct orientation and binding of the substrate and the electron transfer reactivity. For instance, F265A mutation did not improve the oxidation of any of the bulky phenols tested due to the lack of proper hydrophobic interactions between the phenolic substrate and the replaced residue. In fact, the requirement of Phe in position 265 to bind and stabilize bulky hydrophobic aromatic compounds in the substrate binding site of TvL had been previously suggested [22]. The hydrophobic recognition of the substrate by the hydrophobic residues delimiting the enzyme pocket is supposed to be the first step of the mechanism of interaction between xylidine and laccase [23].

The H-bonding of the substrate with an Asp (or Glu) residue fully conserved in fungal laccases and located at the bottom of the binding pocket is also an important structural feature of the active site (Fig. 3) [17, 24-26]. The carboxylate group (Asp206 in TvL) is deprotonated at physiological $\mathrm{pH}$ (pKa 3.9). Hence, substrates bearing $-\mathrm{OH}$ and $-\mathrm{NH}_{2}$ groups are dragged inside by this negative charge and directed to the His ligand (His458 in TvL). While the electron is transferred to $\mathrm{T} 1 \mathrm{Cu}$ through the His ligand, the Asp residue assists the deprotonation of the substrate, thus providing a concerted electron/proton transfer mechanism for the oxidation of phenolic substrates [27]. The lower efficiency of TvL to oxidize phenolic compounds at $\mathrm{pH} 3$ has been attributed to the poorer ability of the protonated Asp206 to drag the substrate inside the active site [20]. The role of the conserved carboxylic group in fungal laccases to assist the abstraction of the proton from the phenolic group of the substrate was demonstrated by directed mutagenesis studies in TvL [28] and in Melanocarpus albomyces laccase (MaL) [29]. A substantial decrease of TvL catalytic activity for 2,6-dimethoxyphenol (DMP), mainly due to remarkable increase of $K_{\mathrm{m}}$, was obtained by replacing the Asp for Asn or Ala residues. Besides, Asp206 stabilized the incipient radical cation of 2,5-xylidine resulting from the electron withdrawal by 
His458 [28]. Likewise, $k_{\text {cat }}$ dropped 30 -fold in MaL for DMP oxidation when Glu235 was changed for Thr [29].

Although the change of the acidic residue by non-acidic ones produced a shift of the optimum $\mathrm{pH}$ to more neutral values for the oxidation of DMP, no shift was obtained for the oxidation of ABTS $[28,29]$. The distinct effect of the point mutations for the enzymatic oxidation of both substrates might be explained by dissimilar oxidation mechanisms, with (DMP) or without (ABTS) proton transfer [30]. Electrostatic interactions with the protonated Asp of the protein active site appear to be crucial for anchoring the negatively charged ABTS, thus explaining the higher activity of fungal laccases towards ABTS at $\mathrm{pH}$ 2-3 [9]. This assumption has been recently confirmed by the correlation between the net charge of the laccase binding pocket and the $K_{\mathrm{m}}$ values for ABTS in four $T$. versicolor laccase isoenzymes [31]. In the computational simulations, the best binding modes were obtained with the isoenzyme with the smallest measured $K_{\mathrm{m}}$ for ABTS at $\mathrm{pH}$ 2. ABTS was bound in a semi-extended conformation with one buried sulfonate group interacting with protonated Asp206 and the other sulfonate interacting with the Arg161. Residue Asp205 was also analyzed in POXA1b from Pleurotus ostreatus by site-directed mutagenesis. Its replacement by Arg not only significantly worsened the catalytic properties towards ABTS, DMP and syringaldazine (SGZ), but decreased protein stability [32].

\section{Intramolecular electron transfer and oxygen reduction}

It is generally accepted that $\mathrm{O}_{2}$ is reduced in the TNC in two consecutive 2-electron steps. In the first one, the donation of two electrons from the $\mathrm{T} 3 \mathrm{Cu}$ ions of the fully reduced enzyme to $\mathrm{O}_{2}$ generates the peroxy intermediate. In the second step, the donation of two electrons from the $\mathrm{T} 1$ and $\mathrm{T} 2 \mathrm{Cu}$ ions to obtain water renders the fully oxidized native (catalytic) intermediate of the enzyme [33, 34]. A different mechanism has been reported for SLAC from S. coelicolor. A Tyr residue (Tyr108) placed at the vicinity of $\mathrm{T} 2$ site can provide one of the four electrons required for the reduction of $\mathrm{O}_{2}$, leading to the transient appearance of a Tyr radical, as demonstrated by the absence of radical in Y108A and Y108F mutants. Tyr acts as a kinetic buffer of redox equivalents to prevent the generation of harmful reactive oxygen species when the reducing substrate is limited [35].

The T1 site is coupled to the TNC through the highly conserved Cys-His bridge that provides a rapid intramolecular electron transfer pathway (Fig. 1). However, the role of neighboring residues to regulate the intramolecular electron transfer from $\mathrm{T} 1$ to the $\mathrm{TNC}$ or to assist the reductive cleavage of the $\mathrm{O}-\mathrm{O}$ bond is not completely elucidated. Site-directed mutagenesis of the His ligands of $\mathrm{T} 3 \mathrm{Cu}$ in Fet3p raised the covalency of the T1Cys(S) bond and reduced its redox potential. By contrast, the redox potential of the $\mathrm{T} 1 \mathrm{Cu}$ in $R$. vernicifera laccase would not be controlled by the redox states of the TNC due to a mechanism for regulating the intramolecular electron transfer from T1 to TNC [36].

The intramolecular electron transfer proceeds together with a proton transfer, required for the reduction of $\mathrm{O}_{2}$ to water, via ionizable groups placed within the access and exit channels to the TNC. Despite the differences existing among MCOs for oxygen binding [37], two acid residues strictly conserved in MCOs have a crucial role in $\mathrm{O}_{2}$ reduction, as demonstrated by site-directed mutagenesis in B. subtilis CotA laccase [38-40], E. coli $\mathrm{CueO}$ [41-43], and yeast Fet $3 p[44,45]$. A Glu residue forms an H-bond with one His ligand of $\mathrm{T} 3 \mathrm{Cu}[8,44,46,47]$. The absence of this Glu residue at the entrance channel to the TNC of CotA laccase (E498L or E498T mutants) caused over $99 \%$ activity loss due to a remarkable drop of $k_{\text {cat }}$, whereas the E498D mutant retained enzymatic activity and showed similar oxygen affinity. These data suggested the important role of Glu (and in a lesser extent of an Asp) in this position in providing protons for the reduction of oxygen and also in its binding [40]. X-ray crystal structure analyses of E. coli CueO mutants proved that the H-bond network built by the Glu residue and water molecules acts as the pathway of proton relay from solvent waters to the TNC for oxygen reduction. The total collapse of the H-bond network in E506I mutant accounted for the complete loss of activity [42].

An Asp residue, which is also part of the H-bond network around the $\mathrm{TNC}$ in close proximity to $\mathrm{T} 2 \mathrm{Cu}$, is a key residue as a proton donor to assist the reductive cleavage of the $\mathrm{O}-\mathrm{O}$ bond, providing the rapid conversion of $\mathrm{O}_{2}$ to water [14, 39, 41]. First mutagenesis studies carried out on this residue in Fet3p (Asp94) demonstrated its role in the decay of the peroxide intermediate [45]. D94E mutation did not affect the initial reaction with $\mathrm{O}_{2}$ but markedly diminished the decay of the peroxide intermediate. The D94A mutation caused larger structural changes that made the TNC unreactive towards $\mathrm{O}_{2}$, demonstrating also a structural role for Asp94. Saturated mutagenesis of this residue (Asp116) in CotA laccase corroborated its importance. The absence of a carboxylate group impaired the decay of the peroxide intermediate and strong depletion of the catalytic activity, downshift of optimal $\mathrm{pH}$ and perturbation of the properties of $\mathrm{T} 1 \mathrm{Cu}$ were observed in all mutants [39]. However, neither the structure of TNC nor the oxygen affinity was affected upon mutation, by contrast to what was reported for Myrothecium verrucaria bilirubin oxidase, yeast Fet3p or E. coli $\mathrm{CueO}[14,41,44]$. The negative charge of Asp116 (which remains deprotonated in the entire $\mathrm{pH}$ range) would supply protons to the $-\mathrm{OH}$ 
groups bound to $\mathrm{T} 2 \mathrm{Cu}$ and control the protonation of Glu498, the sole protonable residue in the vicinity of TNC [39].

\section{To the engineering of improved biocatalysts}

\section{Enhancement of heterologous expression}

Due to their fast growth rate, easy genetic manipulation and availability of numerous molecular biology tools, E. coli and Saccharomyces cerevisiae are the most commonly used expression hosts in protein engineering. However, very frequently, expression is hampered by differences between the organism of origin and the heterologous host, such as codon usage, chaperones to assist protein folding, and post-translational modifications (glycosylation, disulfide bonds, secretion signals, etc.). Heterologous expression is particularly troublesome in the case of fungal laccases, so that the increase of expression yields has constituted, in itself, a target for directed evolution.

Soluble expression in $E$. coli of the endospore laccase from Bacillus licheniformis, similar to B. subtilis CotA laccase, was enhanced 11-fold by a combination of random and site-directed mutagenesis [48]. One of the selected mutations (D500G) was found adjacent to the axial Met of $\mathrm{T} 1 \mathrm{Cu}$, being responsible for an eightfold increase of soluble expression. An Asp residue in this position has only been found in laccases from Bacillus genus, whereas other bacterial and fungal laccases present a Gly. This mutation was later introduced in laccase from Bacillus sp. HR03, also giving rise to a threefold increased expression in E. coli [49].

In the case of fungal laccases, the preferred expression host for directed evolution has traditionally been $S$. cerevisiae. Heterologous expression of $M$. thermophila laccase (MtL) in this yeast was improved eightfold after ten rounds of error-prone PCR and in vivo shuffling [50]. Of all the mutations selected in the final evolved mutant, three mutations were located in different processing sites: two in the native signal propeptide and one in the C-terminus. In particular, the one at the $\mathrm{C}$-terminus was the single mutation responsible for the highest total activity increase. It introduced a new KEX2 protease cleavage site, probably allowing C-tail trimming in the yeast host. C-tail processing has been described to be essential for activity in several ascomycete laccases [51, 52].

For the directed evolution of the high-redox potential laccases (HRPLs) from the basidiomycetes PM1 (PM1L) and Pycnoporus cinnabarinus (PcL), their cDNAs were fused to $S$. cerevisiae's alpha mating factor prepro-leader sequence [53, 54]. By performing random mutagenesis over the whole fusion gene, expression and activity could be enhanced simultaneously. In combination with other mutations in the mature laccase sequence that could also favor expression in yeast (including synonymous mutations that increased codon usage), mutant signal peptides provided expression yields of up to $8 \mathrm{mg} / \mathrm{L}$. In particular, the evolved alpha-factor prepro-leader obtained during the directed evolution of $\mathrm{PcL}$ alone was responsible for a 40-fold increase in expression.

The evolved prepro-leaders showed similar mutations in the hydrophobic core of the preleader $(\mathrm{A}[\alpha 9] \mathrm{D}$ in $\mathrm{PcL}$ and $\mathrm{V}[\alpha 10] \mathrm{D}$ in PM1L evolved variants), which is involved in the translocation of the nascent polypeptide to the ER. These mutations could be exchanged between both laccases, giving rise to similar increases in extracellular activity [54]. Another similarity was found in the spacer sequence between the alpha-factor prepro-leader and the mature laccases, which presents the motif EAEA for cleavage by STE13. In both PcL and PM1L evolved variants, the EAEA motif was disrupted by mutations E[ $\alpha 86] \mathrm{G}$ and $\mathrm{A}[\alpha 86] \mathrm{T}$, respectively. N-terminal sequencing of PM1L evolved variant confirmed the extension of the N-terminus by six amino acids. This misprocessing by STE13 resulted beneficial as demonstrated by the $40 \%$ decrease on laccase secretion when a truncated variant without these extra amino acids was produced [55].

Improving the catalytic activity and substrate specificity

The advances made in the knowledge of laccase structurefunction relationships and the availability of quite a number of laccase crystal structures have facilitated the rational design of laccases for specific targets. It can be assumed that substitutions on amino acids located in the substrate binding pocket or in the vicinity of the catalytic coppers will affect activity. However, beneficial mutations located far from these sites have also been found to affect the overall enzyme activity in directed evolution studies (Fig. 4), highlighting the power of directed evolution to reveal new targets for protein engineering.

The substrate binding pocket of SLAC from S. coelicolor has been re-designed by site-directed mutagenesis to improve its activity towards compounds of interest as redox mediators. The replacement of the two Met of the pocket by small residues (Ala or Gly) remarkably increased the catalytic efficiency with DMP and the decolorization of indigo carmine mediated by methyl syringate or TEMPO [56]. The residues of the substrate binding pocket of CotA laccase were randomly modified by saturated mutagenesis to increase the specificity of the enzyme for ABTS over SGZ. The final mutant laccase (G417L and L386W) was 132 times more specific than the wild-type enzyme. Both mutated residues sandwiched ABTS, thus providing 
Fig. 4 Protein models of the evolved laccase variants from a basidiomycete PM1 and b Pycnoporus cinnabarinus. Models are based on $2 \mathrm{HRG}$ and 2XYB PDB structures, respectively. Mutations accumulated through evolution are shown as sticks
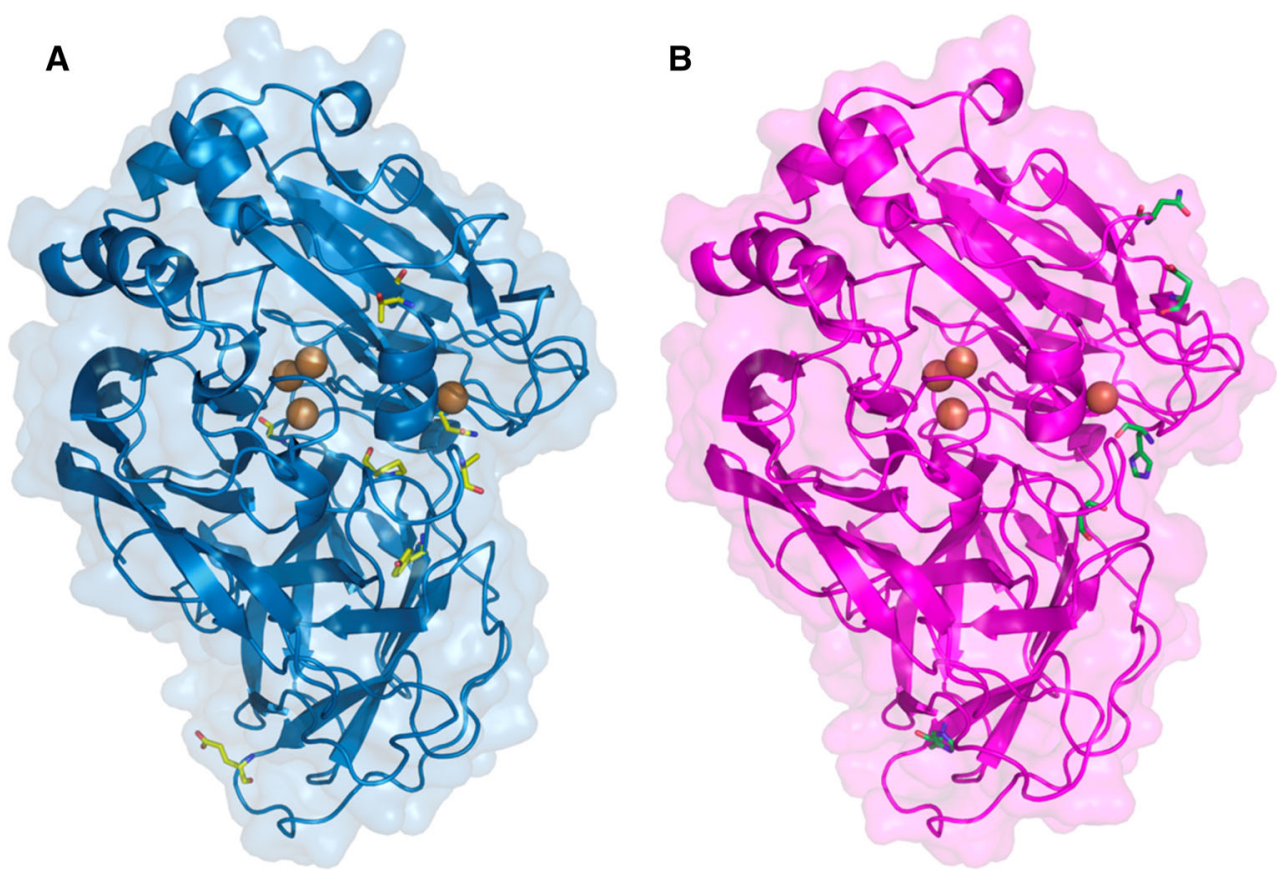

favorable interactions that would enhance the binding of the substrate [57]. In our group, we are re-designing the substrate binding pocket of a chimeric laccase obtained by DNA shuffling of two fungal HRPLs [58] using combinatorial saturation mutagenesis. Mutant libraries are being screened for enhanced activity towards phenolic compounds derived from lignin [5] which might be used as natural mediators of laccases in the lignocellulose biorefineries [59].

The C-terminal tail plays also a critical role on laccase activity. Several site-directed mutagenesis studies have shown that ascomycete laccases typically present a C-terminal extension that acts as a plug that blocks access to the water channel. The crystal structure of M. albomyces laccase (MaL) revealed the penetration of the final four residues into the entrance channel to the $\mathrm{TNC}$, forming an $\mathrm{H}$-bond with one of the His residues that coordinate $\mathrm{T} 3 \mathrm{Cu}$. The deletion of these four residues resulted in an almost inactive laccase, and substitution of the final Leu559 for Ala caused a threefold decrease in specific activity [51]. A C-terminal protrusion that blocks access to the TNC channel has also been described in two laccases from $P$. ostreatus (POXA1b) and Pleurotus eryngii (Ery4), which share $95 \%$ sequence identity and present a 16-residue Ctextension that is not found in other basidiomycete laccases. Curiously, while POXA1b is active when expressed heterologously in yeast, Ery4 is secreted in an inactive form (probably due to incorrect C-terminal processing). Truncated variants at the $\mathrm{C}$-terminal tail were obtained for both laccases. In the case of POXA1b, truncation of 4 or 16 residues increased activity towards the phenolic substrates
DMP and SGZ, but not towards ABTS [32]. On the other hand, deletions ranging from 2 to 18 residues in the C-terminus of Ery4 resulted in active variants, being the 5-less mutant the most catalytically efficient. Furthermore, Lys532 (second to last residue) was crucial for the regulation of enzymatic activity. As in MaL, this residue seems to form a network of $\mathrm{H}$-bonds with residues near the TNC, probably immobilizing the $\mathrm{C}$-terminus inside the water channel and obstructing it. Mutation of Lys532 for Ala or Glu restored laccase activity [60].

When the thermostable laccase from M. thermophila (MtL) was expressed in yeast, $k_{\text {cat }}$ was reduced tenfold for ABTS and 25-fold for SGZ. After ten rounds of directed evolution, wild-type values were recovered for SGZ and doubled for ABTS and, due to the selective pressure introduced during library screening $(\mathrm{pH}$ 6), optimum $\mathrm{pH}$ for ABTS oxidation was shifted from 3 to 4. Surprisingly, of the ten mutations accumulated in the mature evolved laccase, only three of them were located near the catalytic copper ions (Y403H, A108V) or the enzyme pocket $(\mathrm{N} 454 \mathrm{~K})$, while the rest were located in loops or on the protein surface. This first evolved variant has later been used as parent type in a number of directed evolution works for different purposes [61, 62]. In a semi-rational study aimed to enhance catalytic activity and to better understand the role of the $\mathrm{C}$-terminal end in $\mathrm{MtL}$ activity, residues from several conserved regions were targeted for combinatorial saturation mutagenesis [63]. The only nonsynonymous mutation selected after screening 180,000 clones was S510G from the VSG tripeptide of the substrate binding pocket [9], which resulted in higher $k_{\text {cat }}$ values for 
ABTS and DMP and twofold increase in $K_{\mathrm{m}}$ for $\mathrm{O}_{2}$. This mutation causes the disruption of the interaction with the C-terminal plug, thus widening the access of the $\mathrm{O}_{2}$ channel to the TNC. In other evolution studies, two more mutations related to enhanced activity were selected: mutation $\mathrm{N} 552 \mathrm{H}$, located near the C-terminal plug and causing twofold increase in $K_{\mathrm{m}}$ for $\mathrm{O}_{2}$; and mutation L429V, found buried in the substrate binding pocket [64].

For the directed evolution of POXA1b laccase, three rounds of random mutagenesis were performed together with a round of site-directed mutagenesis [65-67]. The final evolved mutant, with five non-synonymous mutations, increased 3.5-fold its activity towards ABTS and twofold towards DMP, and presented higher affinity towards DMP. MD simulations were used to evaluate the effect of some of the mutations selected through the evolution pathway. Mutation L112F, selected in the first generation, was located at the entrance of the water channel that leads to the TNC, and Phe residue could act as a lid that trapped water molecules inside the channel favoring catalysis [65]. Mutation P494T, located at the C-terminal extension of POXA1b, seemed to increase mobility of the loops that form the substrate binding pocket, making the $\mathrm{T} 1 \mathrm{Cu}$ more solvent accessible. Lastly, mutation V148L appeared to affect catalysis by establishing stronger hydrophobic interactions with Tyr208, located in the loop where Asp205 (key to substrate binding) is found.

Random and semi-rational approaches were used in the parallel directed evolution pathways of laccases from basidiomycetes PM1 (PM1L) and P. cinnabarinus (PcL) $[53,54]$. Due to the extremely low expression levels of these laccases in yeast, these studies aimed to increase both secretion and catalytic activity, addressing total activity increases (TAI) for mutant selection. After eight and six generations, TAIs of 34,000- and 8,000-fold were achieved for the evolved variants of PM1L and PcL, respectively. In the case of evolved PM1L, catalytic constants were similar to those of the wild-type enzyme from the fungus [55]. Comparison with the best mutant from the second generation revealed a 13 -fold $k_{\text {cat }}$ improvement for ABTS and ninefold for DMP, suggesting that laccase activity was initially hampered due to the heterologous expression in yeast (as it had been described for MtL [50]). The final evolved variant of PM1L presented seven non-synonymous mutations in the mature laccase sequence, three of which were located near the catalytic center (Fig. 4a). Val162, which is one of the residues that delimits the substrate binding pocket, was substituted for the also hydrophobic but smaller amino acid Ala, probably favoring binding of bulky substrates such as ABTS. Mutations S426N and $\mathrm{A} 461 \mathrm{~T}$, found in the second coordination sphere of $\mathrm{T} 1 \mathrm{Cu}$, established a new network of $\mathrm{H}$-bonds that could change the geometry at the T1 site, affecting the catalytic activity.
As for the evolved PcL, an important broadening of the optimal $\mathrm{pH}$ towards higher values was observed as a consequence of the selective pressure applied during the screening of the mutant libraries, as described for other laccases [50, 65]. By contrast to PM1L, the activity of the native PcL was not affected by the expression in yeast. Even so, $k_{\text {cat }}$ values for ABTS, sinapic acid and DMP were considerably enhanced through evolution, from 10- to 20-fold, with regard to wild-type and native recombinant PcL [53]. The evolved laccase accumulated five amino acid substitutions, three of them considered to be directly related to enhanced activity (Fig. 4b). Mutations N208S and N331D, located at two of the loops that define the substrate binding pocket, could affect substrate recognition. Mutation $\mathrm{P} 394 \mathrm{H}$, selected in the first generation with a TAI of fivefold, is adjacent to His 395 that coordinates $\mathrm{T} 1 \mathrm{Cu}$. This mutation was introduced by site-directed mutagenesis during the engineering of PM1L, causing an important increase in activity (although it was finally discarded due to a somehow negative effect on thermostability). Sitedirected mutagenesis studies currently being carried out in combination with computational simulations corroborate the crucial role of $\mathrm{P} 394 \mathrm{H}$ mutation in the activity enhancement of the final evolved PcL (unpublished data).

\section{Improvement of laccase stability}

For the industrial application of laccases, robust enzymes that are stable and active under harsh operational conditions are needed. Though some studies aimed to increase stability of laccases by site-directed mutagenesis have been reported, to date probably the most significant advances have been achieved by directed molecular evolution, as the structural determinant for protein stability may not be so straightforwardly deduced. By developing appropriate HTS methods, increased stability towards organic solvents, high temperature, or extreme $\mathrm{pH}$ can be obtained after several rounds of directed evolution.

The thermostable POXA1b laccase exhibits a notable stability at alkaline $\mathrm{pH}$ due to the extended $\mathrm{C}$-terminal tail (in particular, the last four residues). Truncated mutants drastically lost the stability at $\mathrm{pH} 10$, while they showed an increased stability at $\mathrm{pH} 5$ [32]. The same effect was observed in truncated variants of Ery4 laccase from $P$. eryngii, for which progressive deletion of residues from the C-terminal tail led to an increased stability at acidic $\mathrm{pH}$. Thermostability was also affected, but there was no direct correlation between the number of residues that were deleted and increased tolerance to high temperature [68]. During directed evolution of POXA1b, mutants with increased stability were obtained. Mutation L112F, selected in the first generation, caused an important decrease in laccase stability. MD simulations showed that the 
substitution of Leu residue for a bulkier Phe caused an increased flexibility of the entire subdomain. This effect was, however, reverted in the following generation thanks to mutation $\mathrm{P} 494 \mathrm{~T}$, which seemed to recover rigidity in this region [65]. When these mutations were combined with those of another stable mutant (K37Q K51N), the stability of both parents towards temperature and $\mathrm{pH} 10$ was inherited and even increased [66].

It is widely accepted that there is a trade-off between enzymatic activity and stability, and very frequently in directed evolution studies mutations that enhance catalysis are destabilizing for the protein. For this reason, it is interesting to introduce stability assays in conjunction with the standard activity assays for the screening of mutant libraries, to enhance stability or to detect destabilizing mutations. During the evolution of basidiomycete PM1 laccase, the use of a thermostability assay [69] enabled the authors to find the mutation responsible for the loss in enzyme stability. Mutation F454S, adjacent to His455 that coordinates $\mathrm{T} 1 \mathrm{Cu}$, improved total activity almost fivefold but at the cost of a decrease of $5{ }^{\circ} \mathrm{C}$ in $\mathrm{T}_{50}$ (the temperature at which the protein retains $50 \%$ of its initial activity after a 10-min incubation) versus parent types [54]. Although successive evolution rounds further increased activity, they did not recover parent $T_{50}$, so this mutation was finally reverted. This way, the final evolved mutant maintained the same $\mathrm{T}_{50}$ as the wild-type laccase (around $73{ }^{\circ} \mathrm{C}$ ).

Zumárraga et al. described the directed evolution of $\mathrm{MtL}$ for increased activity and stability in the presence of organic solvents. After five generations of directed evolution, in which they used a HTS assay based on the oxidation of ABTS with increasing concentrations of ethanol and acetonitrile [70], they achieved a laccase mutant active and stable in high concentrations (up to $50 \%$ ) of cosolvents of different chemical nature [62]. Two mutations in the mature protein, E182K and S280N, were found to establish new stabilizing interactions with surrounding residues.

\section{Chimeric enzymes}

Recombination of related genes allows the exploration of a large sequence space without affecting the structurefunction of a protein, leading to new variants with combined features or unexpected properties by accumulation of neutral mutations that increase the promiscuous functions or robustness of the enzyme [71]. Random recombination of genes by DNA family shuffling or rationally guided recombination after careful inspection of protein structures have been assayed on laccases.

Two chimeric laccases were obtained by exchanging the $\mathrm{N}$-terminal and C-terminal halves of Lcc1 and Lcc4 isoenzymes from Lentinula edodes, in such a way that the resulting hybrids presented two $\mathrm{Cu}$-binding motives from each parent [72]. Lcc1 is secreted in the culture media and presents high activity towards ABTS, while Lcc4 is accumulated in fruiting bodies and is more active towards phenolic compounds. Of the two chimeras, only Lcc4/1 was actively secreted by transformed tobacco cells. This new laccase presented low $K_{\mathrm{m}}$ values for phenolic compounds, similar to those of Lcc4 or even better. However, turnover rates were severely impaired (approximately tenfold respecting Lcc4), although this could be due to decreased reaction rates caused by heterologous expression. Its $\mathrm{pH}$ profile was intermediate to those of the parent laccases, with a similar but less pronounced acidic profile than that of Lcc4. Concerning temperature, all three laccases presented maximum activity at $50{ }^{\circ} \mathrm{C}$. However, while Lcc4 had around $50 \%$ relative activity at $60{ }^{\circ} \mathrm{C}$, Lcc 1 and Lcc4/1 retained $80 \%$ activity.

Similarly, Bleve et al. described the exchange of $\mathrm{N}$-terminal and C-terminal residues between Ery3 and Ery4 laccases from $P$. eryngii [73]. As described above, Ery4 presents sixteen extra residues at the C-terminus and is inactive when expressed in yeast. Ery3, however, does not present this extension and is functionally produced by yeast. The authors constructed three chimeric laccases based on Ery4 scaffold: Ery4 with N-terminus signal peptide from Ery3 (4N3), Ery4 with C-terminus from Ery3 (4C3), and Ery4 with both $\mathrm{N}$ - and C-termini from Ery3 (4NC3). All constructions produced active laccases, even 4N3 variant that maintained the C-terminal extension from Ery4. This highlights the important role of the N-terminus in determining active protein folding. Both chimeras with exchanged C-terminus doubled $k_{\text {cat }}$ values of Ery3 for ABTS and retained activity at $\mathrm{pH}$ 8. 4NC3 was also the most efficient oxidizing phenolic compounds.

The evolved laccase variants of $P$. cinnabarinus $(\mathrm{PcL})$ and basidiomycete PM1 (PM1L) have also been used to create hybrid laccases in a structure-guided manner by exchanging their D2 domains [74] (Fig. 5a, b). In this case, $K_{\mathrm{m}}$ values and $\mathrm{pH}$ profiles of the swapped mutants were intermediate to those of the parent laccases. Unexpectedly, the mutant containing D2 from evolved PcL showed an important increase of over $7{ }^{\circ} \mathrm{C}$ in its $\mathrm{T}_{50}$. Even though D2 from evolved PcL introduced a new glycosylation site in the swapped laccase, the increase in stability was caused only by the new interactions between amino acids, as removal of the $\mathrm{N}$-glycosylation site by site-directed mutagenesis had no negative effect on $\mathrm{T}_{50}$.

DNA recombination can be easily achieved by taking advantage of the high homologous recombination frequency and efficient gap repair machinery of $S$. cerevisiae. Chimeric laccases from Trametes C30 sp. were obtained by this procedure by allowing the sequences for isoenzymes lac1, lac2 and lac5 to recombine individually with lac3, 
Fig. 5 Protein models of chimeric laccases obtained by domain swapping (a, b) and random DNA shuffling $(\mathbf{c}, \mathbf{d})$ of PM1 (blue) and Pycnoporus cinnabarinus (magenta) evolved laccases, showing the fragments inherited from each parent. Models are based on 2HRG or 2XYB PDB structures
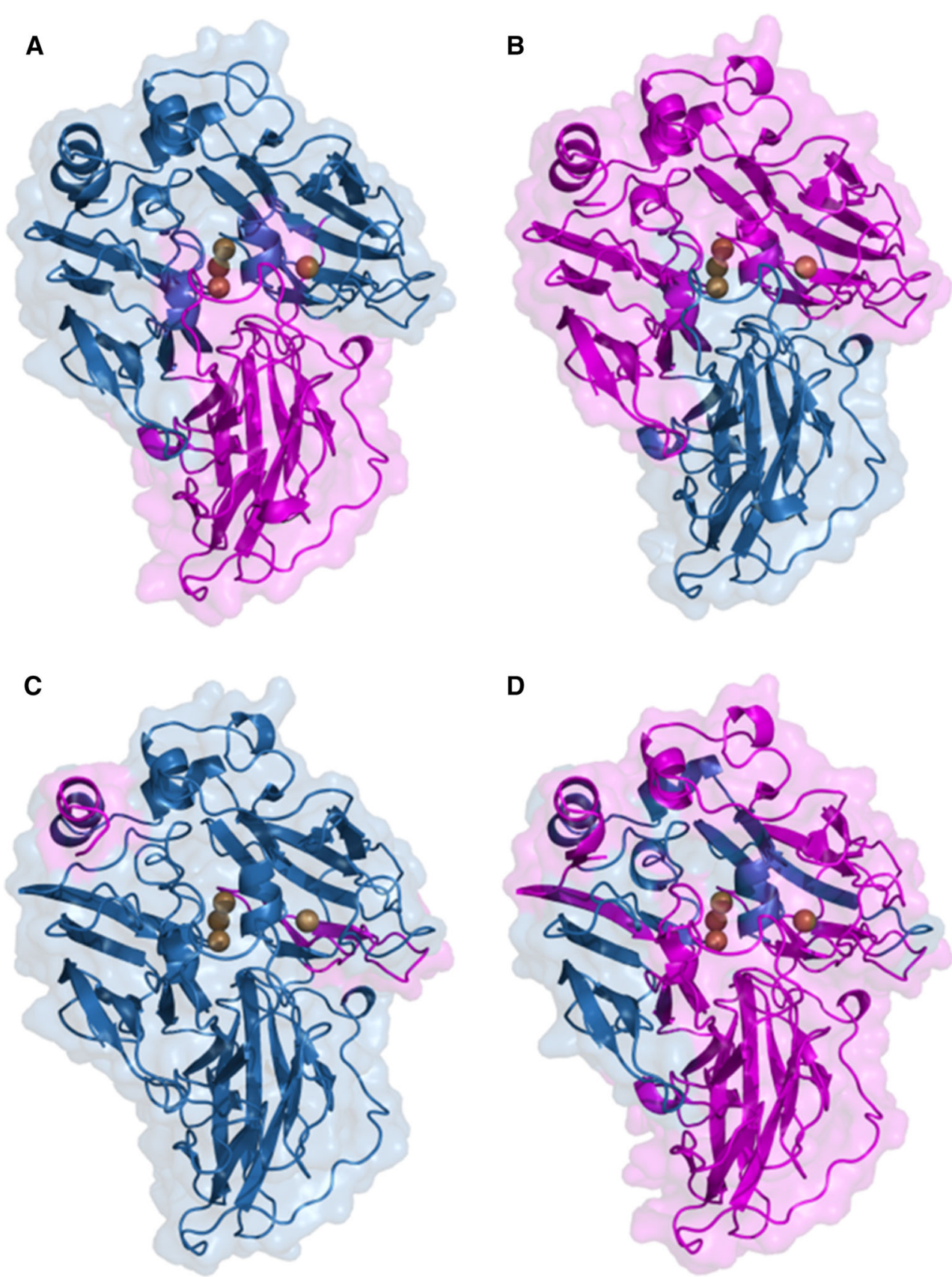

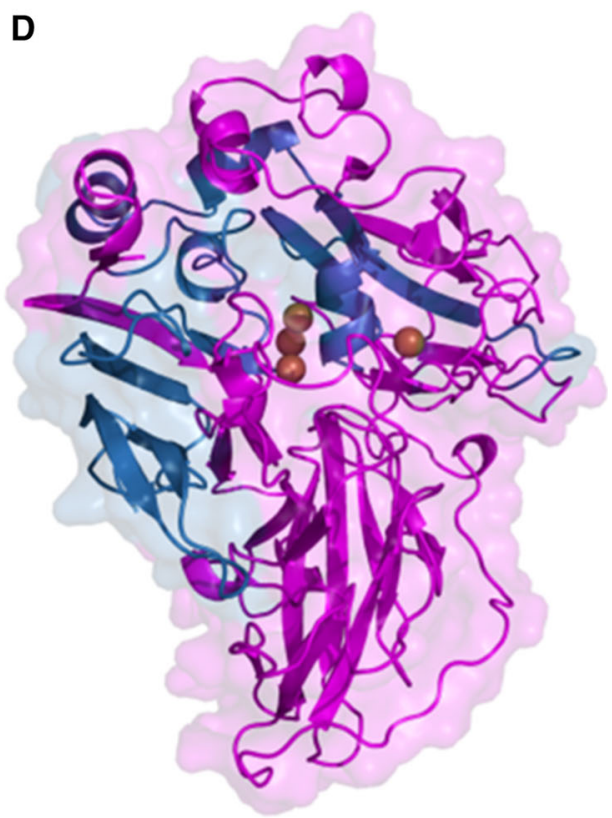

which was actively expressed in highest levels in yeast [75]. Due to the recombination strategy used, the three chimeras studied (namely LAC131, LAC232 and LAC535) presented a central region from LAC3 (around 250 residues on average) and the $\mathrm{N}$ - and $\mathrm{C}$-terminal regions from the different laccases used as "acceptors" (the entire D1 and the final part of D3). All of them presented similar catalytic values to LAC3 at its optimum $\mathrm{pH}$ of 5.7, but LAC131 and LAC232 notably enhanced activity at basic $\mathrm{pH}$ values.

A combination of in vitro and in vivo DNA shuffling was used for random recombination of evolved PcL and
PM1L (76\% sequence identity), and mutants with improved activity were selected in a dual HTS [58]. In this case, the number of crossover events in the mature protein sequence ranged from one to five, introducing 3-31 amino acid substitutions per clone respecting the most similar parent. All recombination events took place at D1 and D3, and many of them close to the conserved copper binding motifs (Fig. 5c, d). This was probably due to the lower sequence identity between the two laccases in D2 respecting D1 and D3 (67 versus 81 and $79 \%$, respectively). Chimeric laccases presented varied $\mathrm{pH}$ profiles for 
ABTS and DMP oxidation, shifted towards more acidic or more neutral $\mathrm{pH}$ values, and some of them even increased $\mathrm{T}_{50}$ of both parent laccases. Better affinities for DMP oxidation at $\mathrm{pH} 5$ were also observed in some selected chimeras. Interestingly, these differences could be found in hybrid laccases that only exchanged a few final residues of the C-terminus, which again highlights its importance in modulating activity and stability.

Laccase engineering beyond the natural limits

By presenting the enzymes to a selective pressure to which they had not been confronted in the course of their natural evolution, directed molecular evolution allows to obtain biocatalysts with properties that are not found in nature. Laccases typically perform their function in an acidic environment, so their optimum activity is generally found below neutral $\mathrm{pH}$ values. It is believed that the excess of $\mathrm{OH}^{-}$ions inhibits electron transfer from $\mathrm{T} 1 \mathrm{Cu}$ to the TNC. However, some of the most important industrial applications of laccases require enzymes that are active at $\mathrm{pH} \geq 7$, such as paper pulp bleaching and decolorization of industrial dyes.

In several directed evolution studies, the $\mathrm{pH}$ activity profiles of the wild-type laccases were shifted in the evolved variants due to the selective pressure applied during mutant library screening [50, 53, 64]. Taking advantage of this fact, MtL mutant [64] was further evolved to enhance its activity at basic $\mathrm{pH}$, while retaining its activity at $\mathrm{pH} 5$, by performing a dual screening [61]. The final evolved mutant, obtained after 5 generations, retained $90 \%$ of maximum ABTS oxidation rate at $\mathrm{pH} 4-6$ and presented $50 \%$ relative activity at $\mathrm{pH}$ 7, a value at which the parent type showed less than $10 \%$. In the case of DMP, optimum $\mathrm{pH}$ was shifted from 4 to 6 , presenting around $80 \%$ relative activity at $\mathrm{pH} 7$. Turnover rates were increased 31-fold for ABTS and ninefold for DMP at $\mathrm{pH}$ 5. Of the mutations accumulated in the final variant, N109S, located near the TNC, seemed to be responsible for these improvements. This mutation disrupts H-bonds with several surrounding residues that include His140 (ligand of one of the T3 Cu) and G558 (part of the C-terminal plug which regulates $\mathrm{O}_{2}$ entry to the $\mathrm{TNC}$ ).

The increasing interest in using laccases (in particular HRPLs) in nanodevices and biosensors resides in their uncommon capability for accepting electrons directly from cathodes, which makes them suitable for the development of biofuel cells required for implantable nanobiodevices. The main drawback is that HRPLs are generally inactive at physiological $\mathrm{pH}$ and are inhibited by chloride concentrations lower than those found in human blood $(150 \mathrm{mM})$ by a similar mechanism to inhibition by $\mathrm{OH}^{-}$. Mate et al. obtained a blood-tolerant laccase by directed evolution [76], combining random, site-directed and saturation mutagenesis of the PM1L evolved variant [54]. They developed a "blood-buffer" for screening mutant libraries that simulated the chemical composition of human blood, gradually increasing buffer $\mathrm{pH}$ from 6.5 to 7.4 throughout four generations. The final evolved variant was active in human plasma and blood. Its $\mathrm{pH}$ activity profile notably shifted from 4 to 5-6 for DMP oxidation and was broadened for ABTS. At $\mathrm{pH} 7$, it retained 50 and $20 \%$ relative activity towards DMP and ABTS, respectively, while activity of the parent type was null. However, turnover rates decreased fourfold and threefold for these substrates at their respective optimum $\mathrm{pH}$. Halide tolerance was also enhanced, raising the $\mathrm{I}_{50}$ for $\mathrm{Cl}^{-}$(concentration at which activity is $50 \%$ of the initial value) from 176 to $1,025 \mathrm{mM}$ when ABTS was used as substrate at $\mathrm{pH}$ 4. At $\mathrm{pH} 7.4$, no negative effect for ABTS oxidation was observed in the range of $100-800 \mathrm{mM} \mathrm{NaCl}$. Both mutations selected in the final evolved mutant, F396I and F454E, were located near the T1 site, in the second coordination sphere. It was hypothesized that these mutations affect electron transfer from the substrate to the $\mathrm{T} 1$ (the rate limiting step), compensating the inhibition caused by $\mathrm{OH}^{-}$and halides at the TNC.

\section{Concluding remarks}

In spite of the huge biotechnological potential of laccases and the existence of some commercial preparations, the implementation of laccases at industrial scale is a pending issue. Today, the use of novel computational methods, and cutting-edge directed evolution techniques, supported by the know-how generated during the last two decades on laccase structure-function relationships, can change this scenario. In this endeavor, rational and evolutionary design will guide the engineering of recombinant biocatalysts better suited for target biotransformations under defined operational conditions. Computational simulations and directed evolution will interact to reveal targets for protein engineering to be explored by site-directed mutagenesis (or semi-rational approaches) or for designing smart libraries to reduce the screening efforts in evolutionary strategies.

Acknowledgments This work has been partially funded by the Spanish project EVOFACEL (BIO2010-1967) and the EU project INDOX (KBBE-2013-7-613549). I. Pardo is grateful to CSIC for JAE-Predoc Fellowship.

Open Access This article is distributed under the terms of the Creative Commons Attribution License which permits any use, distribution, and reproduction in any medium, provided the original author(s) and the source are credited. 


\section{References}

1. Baldrian P (2006) Fungal laccases-occurrence and properties. FEMS Microbiol Rev 30:215-242

2. Skalova T, Dohnalek J, Ostergaard LH, Osteryaard PR, Kolenko P, Duskova J, Stepankova A, Hasek J (2009) The structure of the small laccase from Streptomyces coelicolor reveals a link between laccases and nitrite reductases. J Mol Biol 385:1165-1178

3. Mot A, Silaghi-Dumitrescu R (2012) Laccases: complex architectures for one-electron oxidations. Biochemistry (Mosc) 77(1395-1407):6

4. Alcalde M, Bulter T (2003) Colorimetric assays for screening laccases. Methods Mol Biol 230:193-201

5. Pardo I, Chanaga X, Vicente AI, Alcalde M, Camarero S (2013) New colorimetric screening assays for the directed evolution of fungal laccases to improve the conversion of plant biomass. BMC Biotechnol 13:90

6. Sakurai T, Kataoka K (2007) Structure and function of type I copper in multicopper oxidases. Cell Mol Life Sci 64:2642-2656

7. Hall JF, Kanbi LD, Strange RW, Hasnain SS (1999) Role of the axial ligand in type $1 \mathrm{Cu}$ centers studied by point mutations of Met148 in rusticyanin. Biochemistry 38:12675-12680

8. Durao P, Bento I, Fernandes AT, Melo EP, Lindley PF, Martins LO (2006) Perturbations of the T1 copper site in the CotA laccase from Bacillus subtilis: structural, biochemical, enzymatic and stability studies. J Biol Inorg Chem 11:514-526

9. Xu F, Berka RM, Wahleithner JA, Nelson BA, Shuster JR, Brown SH, Palmer AE, Solomon EI (1998) Site-directed mutations in fungal laccase: effect on redox potential, activity and $\mathrm{pH}$ profile. Biochem J 334:63-70

10. Xu F, Palmer AE, Yaver DS, Berka RM, Gambetta GA, Brown SH, Solomon EI (1999) Targeted mutations in a Trametes villosa laccase-axial perturbations of the T1 copper. J Biol Chem 274:12372-12375

11. Miura Y, Tsujimura S, Kurose S, Kamitaka Y, Kataoka K, Sakurai T, Kano K (2009) Direct electrochemistry of CueO and its mutants at residues to and near type $\mathrm{I} \mathrm{Cu}$ for oxygen-reducing biocathode. Fuel Cells 9:70-78

12. Palmer AE, Szilagyi RK, Cherry JR, Jones A, Xu F, Solomon EI (2003) Spectroscopic characterization of the Leu513His variant of fungal laccase: effect of increased axial ligand interaction on the geometric and electronic structure of the type $1 \mathrm{Cu}$ site. Inorg Chem 42:4006-4017

13. Shimizu A, Sasaki T, Kwon JH, Odaka A, Satoh T, Sakurai N, Sakurai T, Yamaguchi S, Samejima T (1999) Site-directed mutagenesis of a possible type 1 copper ligand of bilirubin oxidase; a Met467Gln mutant shows stellacyanin-like properties. J Biochem Tokyo 125:662-668

14. Kataoka K, Kitagawa R, Inoue M, Naruse D, Sakurai T, Huang HW (2005) Point mutations at the type $\mathrm{ICu}$ ligands, Cys457 and Met467, and at the putative proton donor, Asp105, in Myrothecium verrucaria bilirubin oxidase and reactions with dioxygen. Biochemistry 44:7004-7012

15. Li H, Webb SP, Ivanic J, Jensen JH (2004) Determinants of the relative reduction potentials of type-1 copper sites in proteins. J Am Chem Soc 126:8010-8019

16. Hong G, Ivnitski DM, Johnson GR, Atanassov P, Pachter R (2011) Design parameters for tuning the type $1 \mathrm{Cu}$ multicopper oxidase redox potential: insight from a combination of first principles and empirical molecular dynamics simulations. J Am Chem Soc 133:4802-4809

17. Piontek K, Antorini M, Choinowski T (2002) Crystal structure of a laccase from the fungus Trametes versicolor at $1.90-\AA$ resolution containing a full complement of coppers. J Biol Chem 277:37663-37669
18. Garavaglia S, Cambria MT, Miglio M, Ragusa S, Lacobazzi V, Palmieri F, D'Ambrosio C, Scaloni A, Rizzi M (2004) The structure of Rigidoporus lignosus laccase containing a full complement of copper ions, reveals an asymmetrical arrangement for the T3 copper pair. J Mol Biol 342:1519-1531

19. Cambria MT, Gullotto D, Garavaglia S, Cambria A (2012) In silico study of structural determinants modulating the redox potential of Rigidoporus lignosus and other fungal laccases. J Biomol Struct Dyn 30:89-101

20. Tadesse MA, d'Annibale A, Galli C, Gentili P, Sergi F (2008) An assessment of the relative contributions of redox and steric issues to laccase specificity towards putative substrates. Org Biomol Chem 6:868-878

21. Galli C, Gentili P, Jolivalt C, Madzak C, Vadala R (2011) How is the reactivity of laccase affected by single-point mutations? Engineering laccase for improved activity towards sterically demanding substrates. Appl Microbiol Biotechnol 91:123-131

22. Koschorreck K, Richter SM, Swierczek A, Beifuss U, Schmid RD, Urlacher VB (2008) Comparative characterization of four laccases from Trametes versicolor concerning phenolic $\mathrm{C}-\mathrm{C}$ coupling and oxidation of PAHs. Arch Biochem Biophys 474:213-219

23. Cambria MT, Di Marino D, Falconi M, Garavaglia S, Cambria A (2010) Docking simulation and competitive experiments validate the interaction between the 2,5-xylidine inhibitor and Rigidoporus lignosus laccase. J Biomol Struct Dyn 27:501-509

24. Bertrand T, Jolivalt C, Briozzo P, Caminade E, Joly N, Madzak C, Mougin C (2002) Crystal structure of a four-copper laccase complexed with an arylamine: insights into substrate recognition and correlation with kinetics. Biochemistry 41:7325-7333

25. Kallio JP, Gasparetti C, Andberg M, Boer H, Koivula A, Kruus K, Rouvinen J, Hakulinen N (2011) Crystal structure of an ascomycete fungal laccase from Thielavia arenaria-common structural features of asco-laccases. FEBS J 278:2283-2295

26. Matera I, Gullotto A, Tilli S, Ferraroni M, Scozzafava A, Briganti F (2008) Crystal structure of the blue multicopper oxidase from the white-rot fungus Trametes trogii complexed with p-toluate. Inorg Chim Acta 361:4129-4137

27. Galli C, Madzak C, Vadala R, Jolivalt C, Gentili P (2013) Concerted electron/proton transfer mechanism in the oxidation of phenols by laccase. Chembiochem 14:2500-2505

28. Madzak C, Mimmi MC, Caminade E, Brault A, Baumberger S, Briozzo P, Mougin C, Jolivalt C (2006) Shifting the optimal pH of activity for a laccase from the fungus Trametes versicolor by structure-based mutagenesis. Protein Eng Des Sel 19:77-84

29. Kallio JP, Auer S, Janis J, Andberg M, Kruus K, Rouvinen J, Koivula A, Hakulinen N (2009) Structure-function studies of a Melanocarpus albomyces laccase suggest a pathway for oxidation of phenolic compounds. J Mol Biol 392:895-909

30. Cantarella G, Galli C, Gentili P (2003) Free radical versus electron-transfer routes of oxidation of hydrocarbons by laccasemediator systems. Catalytic and stoichiometric procedures. J Mol Catal B Enzym 22:135-144

31. Christensen NJ, Kepp KP (2014) Setting the stage for electron transfer: molecular basis of ABTS-binding to four laccases from Trametes versicolor at variable $\mathrm{pH}$ and protein oxidation state. J Mol Catal B Enzym 100:68-77

32. Autore F, Del Vecchio C, Fraternali F, Giardina P, Sannia G, Faraco V (2009) Molecular determinants of peculiar properties of a Pleurotus ostreatus laccase: analysis by site-directed mutagenesis. Enzyme Microb Technol 45:507-513

33. Ferraroni M, Myasoedova NM, Schmatchenko V, Leontievsky AA, Golovleva LA, Scozzafava A, Briganti F (2007) Crystal structure of a blue laccase from Lentinus tigrinus: evidences for intermediates in the molecular oxygen reductive splitting by multicopper oxidases. BMC Struct Biol 7:60 
34. Yoon JJ, Solomon EI (2007) Electronic structure of the peroxy intermediate and its correlation to the native intermediate in the multicopper oxidases: insights into the reductive cleavage of the O-O bond. J Am Chem Soc 129:13127-13136

35. Gupta A, Nederlof I, Sottini S, Tepper AW, Groenen EJ, Thomassen EA, Canters GW (2012) Involvement of tyr108 in the enzyme mechanism of the small laccase from Streptomyces coelicolor. J Am Chem Soc 134:18213-18216

36. Augustine AJ, Kragh ME, Sarangi R, Fujii S, Liboiron BD, Stoj $\mathrm{CS}$ et al (2008) Spectroscopic studies of perturbed $\mathrm{T} 1 \mathrm{Cu}$ sites in the multicopper oxidases Saccharomyces cerevisiae Fet3p and Rhus vernicifera laccase: allosteric coupling between the $\mathrm{T} 1$ and trinuclear $\mathrm{Cu}$ sites. Biochemistry 47:2036-2045

37. Bento I, Martins LO, Lopes GG, Carrondo MA, Lindley PF (2005) Dioxygen reduction by multi-copper oxidases; a structural perspective. Dalton Trans 21:3507-3513

38. Silva CS, Damas JM, Chen Z, Brissos V, Martins LO, Soares CM, Lindley PF, Bento I (2012) The role of Asp116 in the reductive cleavage of dioxygen to water in CotA laccase: assistance during the proton-transfer mechanism. Acta Crystallogr Sect D Biol Crystallogr 68:186-193

39. Brissos V, Chen Z, Martins LO (2012) The kinetic role of carboxylate residues in the proximity of the trinuclear centre in the O-2 reactivity of CotA-laccase. Dalton Trans 41:6247-6255

40. Chen Z, Durao P, Silva CS, Pereira MM, Todorovic S, Hildebrandt P, Bento I, Lindley PF, Martins LO (2010) The role of Glu(498) in the dioxygen reactivity of CotA-laccase from Bacillus subtilis. Dalton Trans 39:2875-2882

41. Ueki Y, Inoue M, Kurose S, Kataoka K, Sakurai T (2006) Mutations at Asp112 adjacent to the trinuclear $\mathrm{Cu}$ center in $\mathrm{CueO}$ as the proton donor in the four-electron reduction of dioxygen. FEBS Lett 580:4069-4072

42. Komori H, Kajikawa T, Kataoka K, Higuchi Y, Sakurai T (2013) Crystal structure of the $\mathrm{CueO}$ mutants at Glu506, the key amino acid located in the proton transfer pathway for dioxygen reduction. Biochem Biophys Res Commun 438:686-690

43. Kataoka K, Sugiyama R, Hirota S, Inoue M, Urata K, Minagawa Y, Seo D, Sakurai T (2009) Four-electron reduction of dioxygen by a multicopper oxidase, CueO, and roles of Asp112 and Glu506 located adjacent to the trinuclear copper center. J Biol Chem 284:14405-14413

44. Augustine AJ, Quintanar L, Stoj CS, Kosman DJ, Solomon EI (2007) Spectroscopic and kinetic studies of perturbed trinuclear copper clusters: the role of protons in reductive cleavage of the $\mathrm{O}-\mathrm{O}$ bond in the multicopper oxidase Fet3p. J Am Chem Soc 129:13118-13126

45. Quintanar L, Stoj C, Wang TP, Kosman DJ, Solomon EJ (2005) Role of aspartate 94 in the decay of the peroxide intermediate in the multicopper oxidase Fet3p. Biochemistry 44:6081-6091

46. Messerschmidt A, Huber A (1990) The blue oxidases, ascorbate oxidase, laccase and ceruloplasmin. Modelling and structural relationships. Eur J Biochem 187:341-352

47. Nitta K, Kataoka K, Sakurai T (2002) Primary structure of a Japanese lacquer tree laccase as a prototype enzyme of multicopper oxidases. J Inorg Biochem 91:125-131

48. Koschorreck K, Schmid RD, Urlacher VB (2009) Improving the functional expression of a Bacillus licheniformis laccase by random and site-directed mutagenesis. BMC Biotechnol 9:12

49. Nasoohi N, Khajeh K, Mohammadian M, Ranjbar B (2013) Enhancement of catalysis and functional expression of a bacterial laccase by single amino acid replacement. Int J Biol Macromol 60:56-61

50. Bulter T, Alcalde M, Sieber V, Meinhold P, Schlachtbauer C, Arnold FH (2003) Functional expression of a fungal laccase in Saccharomyces cerevisiae by directed evolution. Appl Environ Microbiol 69:987-995
51. Andberg M, Hakulinen N, Auer S, Saloheimo M, Koivula A, Rouvinen J, Kruus K (2009) Essential role of the C-terminus in Melanocarpus albomyces laccase for enzyme production, catalytic properties and structure. FEBS J 276:6285-6300

52. Fernández-Larrea J, Stahl U (1996) Isolation and characterization of a laccase gene from Podospora anserina. Mol Gen Genet 252:539-551

53. Camarero S, Pardo I, Cañas AI, Molina P, Record E, Martínez AT, Martínez MJ, Alcalde M (2012) Engineering platforms for directed evolution of laccase from Pycnoporus cinnabarinus. Appl Environ Microbiol 78:1370-1384

54. Maté D, García-Burgos C, García-Ruiz E, Ballesteros A, Camarero S, Alcalde M (2010) Laboratory evolution of high redox potential laccases. Chem Biol 17:1030-1041

55. Mate D, García-Ruiz E, Camarero S, Shubin V, Falk M, Shleev S, Alcalde M (2013) Switching from blue to yellow: altering the spectral properties of a high redox potential laccase by directed evolution. Biocatal Biotransform 31:8-21

56. Toscano MD, De Maria L, Lobedanz S, Ostergaard LH (2013) Optimization of a small laccase by active-site redesign. Chembiochem 14:1209-1211

57. Gupta N, Lee FS, Farinas ET (2010) Laboratory evolution of laccase for substrate specificity. J Mol Catal B Enzym 62:230-234

58. Pardo I, Vicente AI, Alcalde M, Camarero S (2012) Development of chimeric laccases by directed evolution. Biotechnol Bioeng 109:2978-2986

59. Cañas AI, Camarero S (2010) Laccases and their natural mediators: biotechnological tools for sustainable eco-friendly processes. Biotechnol Adv 28:694-705

60. Bleve G, Lezzi C, Spagnolo S, Tasco G, Tufariello M, Casadio R, Mita G, Rampino P, Grieco F (2013) Role of the C-terminus of Pleurotus eryngii Ery4 laccase in determining enzyme structure, catalytic properties and stability. Protein Eng Des Sel 26:1-13

61. Torres-Salas P, Mate DM, Ghazi I, Plou FJ, Ballesteros AO, Alcalde M (2013) Widening the $\mathrm{pH}$ activity profile of a fungal laccase by directed evolution. Chembiochem 14:934-937

62. Zumárraga M, Bulter T, Shleev S, Polaina J, Martinez-Arias A, Plou FJ, Ballesteros A, Alcalde M (2007) In vitro evolution of a fungal laccase in high concentrations of organic cosolvents. Chem Biol 14:1052-1064

63. Zumárraga M, Domínguez CV, Camarero S, Shleev S, Polaina J, Martínez-Arias A et al (2008) Combinatorial saturation mutagenesis of the Myceliophthora thermophila laccase T2 mutant: the connection between the C-terminal plug and the conserved (509)VSG(511) tripeptide. Comb Chem High Throughput Screen 11:807-816

64. Zumárraga M, Camarero S, Shleev S, Martinez-Arias A, Ballesteros A, Plou FJ, Alcalde M (2007) Altering the laccase functionality by in vivo assembly of mutant libraries with different mutational spectra. Proteins 71:250-260

65. Festa G, Autore F, Fraternali F, Giardina P, Sannia G (2008) Development of new laccases by directed evolution: functional and computational analyses. Proteins 72:25-34

66. Miele A, Giardina P, Notomista E, Piscitelli A, Sannia G, Faraco V (2010) A semi-rational approach to engineering laccase enzymes. Mol Biotechnol 46:149-156

67. Miele A, Giardina P, Sannia G, Faraco V (2010) Random mutants of a Pleurotus ostreatus laccase as new biocatalysts for industrial effluents bioremediation. J Appl Microbiol 108:998-1006

68. Bleve G, Lezzi C, Mita G, Rampino P, Perrotta C, Villanova L, Grieco F (2008) Molecular cloning and heterologous expression of a laccase gene from Pleurotus eryngii in free and immobilized Saccharomyces cerevisiae cells. Appl Microbiol Biotechnol 79:731-741

69. García-Ruiz E, Maté D, Ballesteros A, Martínez AT, Alcalde M (2010) Evolving thermostability in mutant libraries of ligninolytic oxidoreductases expressed in yeast. Microb Cell Fact 9:17 
70. Alcalde M, Bulter T, Zumárraga M, García-Arellano H, Mencia M, Plou FJ, Ballesteros A (2005) Screening mutant libraries of fungal laccases in the presence of organic solvents. J Biomol Screen 10:624-631

71. Romero PA, Arnold FH (2009) Exploring protein fitness landscapes by directed evolution. Nat Rev Mol Cell Biol 10:866-876

72. Nakagawa Y, Sakamoto Y, Kikuchi S, Sato T, Yano A (2010) A chimeric laccase with hybrid properties of the parental Lentinula edodes laccases. Microbiol Res 165:392-401

73. Bleve G, Lezzi C, Spagnolo S, Rampino P, Perrotta C, Mita G, Grieco F (2014) Construction of a laccase chimerical gene: recombinant protein characterization and gene expression via yeast surface display. Appl Biochem Biotechnol 172:2916-2931
74. Pardo I, Camarero S (2014) Domain swapping between two high redox potential laccases: effect on enzyme properties. In: Proceedings of 13th EWLP, Sevilla, 24-27 June, 631-634

75. Cusano AM, Mekmouche Y, Meglecz E, Tron T (2009) Plasticity of laccase generated by homeologous recombination in yeast. FEBS J 276:5471-5480

76. Mate D, González-Pérez D, Falk M, Kittl R, Pita M, De Lacey AL, Ludwig R, Shleev S, Alcalde M (2013) Blood tolerant laccase by directed evolution. Chem Biol 20(2):223-231 